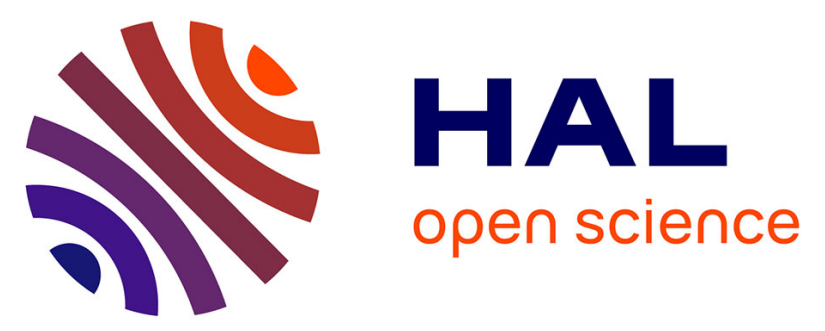

\title{
Mesenchymal stromal cells orchestrate follicular lymphoma cell niche through the CCL2-dependent recruitment and polarization of monocytes.
}

Fabien Guilloton, Gersende Caron, Cédric Ménard, Céline Pangault, Patricia Amé-Thomas, Joëlle Dulong, John de Vos, Delphine Rossille, Catherine Henry, Thierry Lamy, et al.

\section{To cite this version:}

Fabien Guilloton, Gersende Caron, Cédric Ménard, Céline Pangault, Patricia Amé-Thomas, et al.. Mesenchymal stromal cells orchestrate follicular lymphoma cell niche through the CCL2-dependent recruitment and polarization of monocytes.: CCL2 AND FOLLICULAR LYMPHOMA CELL NICHE. Blood, 2012, 119 (11), pp.2556-67. 10.1182/blood-2011-08-370908 . inserm-00665887

\section{HAL Id: inserm-00665887 https://www.hal.inserm.fr/inserm-00665887}

Submitted on 3 Aug 2012

HAL is a multi-disciplinary open access archive for the deposit and dissemination of scientific research documents, whether they are published or not. The documents may come from teaching and research institutions in France or abroad, or from public or private research centers.
L'archive ouverte pluridisciplinaire HAL, est destinée au dépôt et à la diffusion de documents scientifiques de niveau recherche, publiés ou non, émanant des établissements d'enseignement et de recherche français ou étrangers, des laboratoires publics ou privés. 


\title{
Mesenchymal stromal cells orchestrate follicular lymphoma cell niche through the CCL2-dependent recruitment and polarization of monocytes
}

\author{
Fabien Guilloton ${ }^{1}$, Gersende Caron ${ }^{1,2}$, Cédric Ménard ${ }^{1,2}$, Céline Pangault ${ }^{1,2}$, \\ Patricia Amé-Thomas ${ }^{1,2}$, Joëlle Dulong ${ }^{1}$, John De Vos ${ }^{3}$, Delphine Rossille ${ }^{4}$, Catherine \\ Henry $^{2}$, Thierry Lamy ${ }^{1,5}$, Olivier Fouquet ${ }^{6}$, Thierry Fest ${ }^{1,2}$, and Karin Tarte ${ }^{1,2}$ \\ 1 INSERM U917, Université Rennes 1, EFS Bretagne, France \\ 2 Pôle Cellules \& Tissus, CHU Pontchaillou, Rennes, France \\ 3 Institut de Recherche en Biothérapie, Hôpital Saint-Eloi, CHU Montpellier, \\ France \\ $4 \quad$ INSERM U936, Université de Rennes 1, France \\ 5 Service d'Hématologie Clinique, CHU Pontchaillou, Rennes, France \\ 6 Service de Chirurgie Thoracique et Cardiovasculaire, CHU Pontchaillou, \\ Rennes, France \\ Running title: \\ Scientific heading: \\ Text word count: \\ Abstract word count: \\ Figure/Table count: \\ Reference count: \\ Supplemental Figures: \\ Supplemental Tables:
}

Corresponding author: Karin Tarte

INSERM U917

Faculté de médecine - 2 Avenue du Pr Léon Bernard 35043 RENNES - France

e-mail: karin.tarte@univ-rennes1.fr

Phone: +33 223234512

Fax:+33223234958 


\section{Abstract}

Accumulating evidence indicates that infiltrating stromal cells contribute directly and indirectly to tumor growth in a wide range of cancers. In follicular lymphoma (FL), malignant $B$ cells are found admixed with heterogeneous lymphoid-like stromal cells within invaded lymph nodes and bone marrow (BM). In addition, mesenchymal stromal cells (MSC) support in vitro FL B-cell survival, in particular after their engagement towards lymphoid differentiation. We show here that BM-MSC obtained from FL patients (FL-MSC) display a specific gene expression profile compared to MSC obtained from healthy age-matched donors (HD-MSC). This FL-MSC signature is significantly enriched for genes associated with a lymphoid-like commitment. Interestingly, CCL2 could be detected at a high level within FL cell niche, is upregulated in HD-MSC by coculture with malignant $B$ cells, and is overexpressed by FL-MSC, in agreement with their capacity to recruit monocytes more efficiently than HD-MSC. Moreover, FL-MSC and macrophages cooperate to sustain malignant Bcell growth whereas FL-MSC drive monocyte differentiation towards a proangiogenic and LPS-unresponsive phenotype close to that of tumor-associated macrophages. Altogether, these results highlight the complex role of FL stromal cells that promote direct tumor B-cell growth and orchestrate FL cell niche, thus emerging as a potential therapeutic target in this disease. 


\section{Introduction}

Tumorigenesis is widely recognized as a non cell-autonomous process depending on an intricate network of surrounding accessory supportive cells ${ }^{1}$. Among this neoplastic microenvironment, cancer-associated fibroblasts (CAF) are phenotypically and functionally distinct from their normal counterpart, thus providing a niche-based model of oncogenesis resulting from the dynamic co-evolution of both cancer and stromal cells ${ }^{2,3}$. CAF phenotype and molecular signatures are strongly heterogeneous but are generally maintained in culture, implying stable alterations. This heterogeneity could be associated in part to tumor type and localization but is also probably ascribed to the diverse origins of CAF, which have been reported to derive from resident local fibroblasts, from bone marrow (BM)-derived mesenchymal progenitors, or from passenger stromal cells brought with tumor cells. In particular, mesenchymal stromal cells (MSC) could be recruited within tumors where they incorporate into the stroma, become activated, and potentiate tumor growth in coinjection studies ${ }^{4}$. MSC have been shown to differentiate into CAF-like cells in vitro after exposure to cancer cell conditioned medium ${ }^{5}$ and to stimulate tumor survival and proliferation, angiogenesis, and metastastic spread in experimental xenograft models ${ }^{6,7}$. Even if few data are available on MSC derived from cancer patients, BMMSC from patients with multiple myeloma (MM) were shown to have a distinct molecular signature and to support more efficiently the growth of malignant plasma cells than BM-MSC obtained from healthy donors $(\mathrm{HD})^{8}$.

Interestingly, it was recently demonstrated that solid tumors could direct the reorganization of surrounding stroma into lymphoid-like stromal structures involving fibroblastic reticular cells (FRC)-like cells ${ }^{9,10}$. Within normal lymph node (LN), FRC produce and ensheathe collagen bundles and other extracellular matrix components, building an enclosed conduit system involved in the delivery of small molecules, such as chemokines and antigens, to the T-cell zone. Moreover, FRC provide a foothold for immune cell recruitment, motility, interaction, and homeostasis ${ }^{11}$. We have previously demonstrated that $\mathrm{LN}$ contained bona fide MSC and that human BM-MSC as well as LN-MSC could be committed to FRC differentiation in response to a combination of tumor necrosis factor alpha (TNF) and lymphotoxin alpha1beta2 (LT), the two main factors involved in the differentiation and maintenance of secondary 
lymphoid organs ${ }^{12}$. Nevertheless, the precise relationships between MSC, FRC, and CAF remain elusive.

Follicular lymphomas (FL) are the most frequent indolent non-Hodgkin's lymphomas $(\mathrm{NHL})$ and result from the transformation of germinal center (GC)-derived $B$ cells retaining a strong dependence on their specific lymphoid microenvironment ${ }^{13}$. In agreement, gene expression profiling (GEP) revealed that the outcome of patients with $\mathrm{FL}$ is primarily predicted by specific gene signatures of non-malignant tumorinfiltrating cells ${ }^{14}$. More recently, immunohistochemical studies have proposed a large panel of predictive markers reflecting the number, activation, and/or spatial distribution of infiltrating immune cells, in particular $T$ cells and tumor-associated macrophages $(T A M)^{15}$. Concerning stromal cell niche in FL, FRC meshwork is expanded and activated within invaded $\mathrm{LN}^{16}$ and in vitro functional studies have underlined that mesenchymal cells recruit malignant $B$ cells and protect them from spontaneous and drug-induced cell death ${ }^{12,17,18}$. In addition, stromal cells may also interact with FL infiltrating immune cells to indirectly favour lymphoma progression. Interestingly, FL is generally a disseminated disease with initial involvement of both $\mathrm{LN}$ and $\mathrm{BM}^{19}$. Moreover, $\mathrm{BM}$ infiltration is characterized by the ectopic development of lymphoid-like stromal cells of heterogeneous phenotype that are found admixed with malignant $\mathrm{B}$ cells ${ }^{20}$. Whether these cells actually arise from in situ differentiation of resident MSC is unknown. We previously showed that MSC-derived FRC-like cells display an increased capacity to sustain FL B-cell survival and that primary purified malignant $B$ cells could promote FRC differentiation ${ }^{12}$. These results suggest that malignant $B$ cells can endow their stromal microenvironment with supportive properties. Within the BM, malignant $B$ cells retained their main follicular features and undergo independent intraclonal evolution ${ }^{21}$ suggesting that the BM provides a preferred non-lymphoid tumor microenvironment that would be very useful to study stromal alterations.

To better understand characteristics and functions of stromal cells in FL we investigated GEP of BM-MSC from $\mathrm{FL}$ patients pertaining to lymphoid stroma signature and explored the functional implications of the specific FL-MSC signature. In particular, we highlighted the role of FL-associated stromal cells in the recruitment and polarization of monocytes into TAM-like cells. Combined with our previous studies, this work draw a more complete picture of how MSC contribute to FL 
lymphomagenesis, through a dual role involving a direct B-cell supportive effect and an indirect activity on the orchestration of FL cell niche. 


\section{Materials and Methods}

\section{Patients and cell samples}

Subjects were recruited under institutional review board approval and informed consent process according to the Declaration of Helsinki. BM aspirates were obtained from FL patients at diagnosis and from HD undergoing cardiac surgery. Clinical characteristics of the $10 \mathrm{FL}$ patients used to obtain FL-MSC GEP are listed in Supplemental Table S1.

BM plasma were collected by centrifugation and frozen until use. BM mononuclear cells (BM-MNC) were isolated by Ficoll density gradient and seeded at $10^{4}$ cells $/ \mathrm{cm}^{2}$ in $\alpha$-MEM (Life Technologies, Carlsbad, CA) supplemented with $10 \%$ screened fetal calf serum (FCS, Hyclone, Logan, UT), $100 \mathrm{IU} / \mathrm{mL}$ penicillin, $100 \mu \mathrm{g} / \mathrm{mL}$ streptomycin, and $1 \mathrm{ng} / \mathrm{ml}$ fibroblast growth factor 2 (FGF-2, R\&D Systems, Abingdon, UK) ${ }^{22}$. Non adherent cells were discarded after 2 days of culture and adherent cells were replenished twice a week with fresh culture medium until confluence (P0). BM-MSC were then harvested using trypsin, and seeded at 500 cells $/ \mathrm{cm}^{2}$ until confluence (first passage, P1). The frequency of colony-forming unit-fibroblast (CFU-F) in BM-MNC was evaluated in parallel for all MSC batches. At day 10, cells were stained with MayGrunwald-Giemsa and colonies with more than 50 cells were counted. The growth kinetic was assessed by the number of population doubling (PD) calculated as: Log(number of cells at the end of passage/number of seeded cells)/Log2, where the number of seeded cells for PO was the number of CFU-F within BM-MNC. The complete phenotype of all HD-MSC and FL-MSC batches was performed at the end of $\mathrm{P} 1$ before microarray experiments (see supplemental data). In addition, BM-MSC were used at passages 2 to 3 for functional studies.

Primary malignant B cells from FL lymph nodes were purified by negative selection as described ${ }^{23}$. Peripheral blood monocytes were obtained by elutriation (J6 centrifuge, Beckman Coulter, Villepinte, France) followed by an additional depletion of residual T cells using anti-CD3 microbeads (Miltenyi Biotech, Bergisch Gladbach, Germany). Only cell fractions with at least $98 \%$ cell purity as evaluated by flow cytometry were used for further experiments. BL2, VAL, and RL GC-derived lymphoma B-cell lines were maintained in RPMI1640-10\% FCS. 


\section{GEP study}

GEP was performed on 10 BM-MSC obtained from FL patients (FL-MSC) and from 6 age-matched HD (HD-MSC) treated or not for 3 days by TNF $(10 \mathrm{ng} / \mathrm{mL})$ and LT (100ng/mL, R\&D Systems, Abingdon, UK) to induce their FRC-like differentiation ${ }^{12}$. RNA was extracted using AllPrep ARN/ADN/protein kit (Qiagen, Valencia, CA) and RNA purity and integrity was checked using the Bioanalyzer 2100 (Agilent, Santa Clara, CA). All samples used for microarray experiments displayed a RNA integrity number (RIN) above 8.9. Biotinylated cRNA were amplified according to the small sample labelling protocol (TwoCycle amplification kit, Affymetrix, Santa Clara, CA) and hybridized on GeneChip HG-U133 Plus 2.0 oligonucleotide microarrays (Affymetrix). Data analyzes were performed using Partek Genomics Suite (Partek, St Louis, MO) as described in Supplemental data. All microarray data are available on the Gene Expression Omnibus (GEO) under accession number GSE35331

\section{Real-time quantitative PCR (RQ-PCR)}

cDNA synthesis was performed on $1 \mu \mathrm{g}$ total RNA using the Superscript II reverse transcriptase and random hexamers (Invitrogen, Carlsbad, CA). We used then specific Taqman Gene Expression Assays (Supplemental Table S2) and the TaqMan Universal master mix (Applied Biosystems, Foster City, CA). GAPDH was determined as an appropriate internal standard gene. Gene expression was measured using the ABI Prism 7700 Sequence Detection System based on the $\Delta C_{T}$ calculation method.

\section{$B$-cell growth assays}

After serum deprivation, BL2 $\left(2.5 \times 10^{4}\right.$ cells $\left./ \mathrm{mL}\right), \mathrm{RL}$, or VAL $\left(1.25 \times 10^{4}\right.$ cells $\left./ \mathrm{mL}\right)$ were seeded with low serum concentration in the presence or not of a confluent MSC monolayer pretreated or not with TNF/LT for 3 days. When indicated, we used as feeder cells in vitro differentiated macrophages, obtained by a 4-day culture of purified monocytes with $10 \mathrm{ng} / \mathrm{mL}$ macrophage-colony stimulating factor (M-CSF, R\&D Systems) in the presence or not of FL-MSC (ratio 3/1). MSC and macrophages were extensively washed before the 3-day coculture with $B$ cells. Cells were pulsed with $1 \mu \mathrm{Ci} /$ well tritiated thymidine $\left({ }^{3} \mathrm{H}-\mathrm{TdR}\right.$, Perkin Elmer, Courtaboeuf, France) for the last 16 hours of culture, harvested, and counted on a liquid scintillation analyzer. For primary FL samples, purified malignant B cells $\left(7.5 \times 10^{5}\right.$ cells $\left./ \mathrm{mL}\right)$ were seeded in 
RPMI1640-10\% FCS in the presence or not of FL-MSC and/or macrophages. After 7 days of culture, non-adherent and adherent cells were collected, pooled, and the absolute number of $\mathrm{CD} 19 / \mathrm{CD} 20^{\text {pos }} \mathrm{CD} 105^{\text {neg }} \mathrm{CD} 14^{\text {neg }}$ TOPRO- $3^{\text {neg }}$ viable $\mathrm{B}$ cells was evaluated using FlowCounts beads (Beckman Coulter).

\section{B-cell proliferation and apoptosis}

VAL and RL were cultured with low serum concentration alone or in the presence of confluent FL-MSC, in vitro differentiated macrophages, or both. After $24 \mathrm{~h}$, cell apoptosis was analyzed using active caspase- 3 staining gated on CD19/CD20 $0^{\text {pos }} B$ cells. In the same experiments, cell proliferation was analyzed after 3 days using BrdU staining. Briefly, cells were pulsed with 10 $\mu \mathrm{M}$ BrdU (Becton Dickinson) for 30 minutes before cell harvesting and quantification of the percentage of $\mathrm{BrdU}^{\text {pos }}$ cycling cells among CD19/CD20 ${ }^{\text {pos }}$ active caspase- $3^{\text {neg }}$ viable $B$ cells.

\section{CCL2 quantification}

CCL2 was quantified using the DuoSet ELISA kit (R\&D Systems) in BM plasma, in the supernatants of HD-MSC and FL-MSC collected at the end of $P 1$, and in the supernatant of HD-MSC stimulated with TNF/LT or cocultured with RL, VAL, BL2, or purified primary $B$ cells for 3 days.

In order to confirm the stromal origin of secreted CCL2 in B-cell/MSC coculture, both CD19/CD20 ${ }^{\text {pos }} C D 105^{\text {neg }} D A P I^{\text {neg }}$ viable $B$ cells and CD19/CD20 ${ }^{\text {neg }} C D 105^{\text {pos }} D A P I^{\text {neg }}$ viable MSC were sorted using a FACSAria cell sorter (Becton Dickinson, San Diego, $\mathrm{CA}$ ) at the end of the coculture and used to assess CCL2 mRNA expression by RQPCR.

In addition, HD-MSC were cocultured with VAL and RL for 3 days before collection of the supernatant and cell detachment by trypsin. After depletion of residual $B$ cells using anti-CD45 Dynabeads (Invitrogen), HD-MSC cells were seeded again in culture for 10 days at confluence. Supernatants were collected at day 3 and 10 for CCL2 quantification by ELISA.

\section{Migration assay}

Purified monocytes $\left(10^{5}\right.$ cells $/ 100 \mu \mathrm{L}$ ) were added in RPMI1640-1\% FCS (migration medium) to the upper compartment of Transwell chambers with 5 - $\mu \mathrm{m}$ pore filters 
(Costar). Lower chambers contained supernatants obtained after 4 days of culture in migration medium of FL-MSC, HD-MSC, or HD-MSC prestimulated by RL or VAL Bcell lines for 3 days. When indicated, CCL2 was depleted from MSC supernatants. The absolute number of viable monocytes was quantified in the lower chamber after 1.5 hour using FlowCount beads.

\section{Macrophage polarization}

Purified monocytes $\left(1.5 \times 10^{5} \mathrm{cells} / \mathrm{cm}^{2}\right)$ were cultured alone or with MSC $\left(5 \times 10^{4}\right.$ cells $\left./ \mathrm{cm}^{2}\right)$ in the presence of M-CSF. After 1 day of coculture, TNF and IL-10 were quantified in cell supernatants using specific ELISA assays (R\&D Systems and Becton Dickinson; respectively). In parallel, cells were harvested and the expression level of HLA-DR, CD86, and CD14 was evaluated by flow cytometry on $\mathrm{CD} 14^{\text {pos }} \mathrm{CD} 105^{\text {neg }}$ TOPRO- $3^{\text {neg }}$ cells as the ratio of the mean of fluorescence intensity (rMFI) compared to isotype-matched controls. In addition, after 7 days of coculture, cells were stimulated or not with $100 \mathrm{ng} / \mathrm{mL}$ LPS (Invivogen, San Diego, CA) for 5 hours before cell-sorting of $\mathrm{CD} 14^{\text {pos }} \mathrm{CD} 105^{\text {neg }}$ TOPRO- $3^{\text {neg }}$ viable macrophages. RNA was then extracted for RQ-PCR experiments. When specified, the $\gamma$-secretase inhibitor DAPT $(25 \mu \mathrm{M}$, Calbiochem, San Diego, CA) was added to evaluate the role of the Notch pathway. In this case, cell supernatants were collected 18 hours after LPS stimulation for measurement of TNF by ELISA.

\section{Statistical analyses}

Statistical analyses were performed with Prism software (GraphPad Software, La Jolla, CA) using the Wilcoxon or Student's $t$ test for matched pairs or using the MannWhitney nonparametric $U$ test as appropriate. 


\section{Results}

\section{FL-MSC display a specific gene expression profile}

BM-MSC were successfully obtained from all $6 \mathrm{HD}$ and $10 \mathrm{FL}$ patients and the 16 MSC batches displayed similar cell morphology and phenotype including a lack of CD45, CD14, CD34, and CD31 together with a strong expression of CD73, CD90, and CD105 (Figure S1 and Table 1). Moreover, no contamination by $\mathrm{CD} 19^{\text {pos }} \mathrm{B}$ cells could be detected at the end of P1. As BM-MSC growth has been correlated with the age of donors ${ }^{24}$, we selected age-matched HD (Table 1). In these conditions, neither the CFU-F concentration in the BM nor the cumulative population doubling of BMMSC significantly differed between HD and FL patients. Challenging data suggested that $\mathrm{CAF}$ undergo genetic alterations during tumor progression ${ }^{3}$ and microvascular endothelial cells in B-cell lymphomas were reported to harbor lymphoma-specific chromosomal translocations ${ }^{25}$. However, we observed no karyotypic abnormality in HD- or FL-MSC and FISH analysis for $\mathrm{t}(14 ; 18)$ gave consistently negative results including in FL-MSC obtained from patients with $\mathrm{t}(14 ; 18)^{\text {pos }}$ malignant B-cell clones (Figure S2). Recent studies have demonstrated that senescent cells secrete a complex set of proinflammatory and tumor promoting factors ${ }^{26}$. However, HD-MSC and FL-MSC displayed no $\beta$-galactosidase staining at the end of P1 (data not shown) and expressed a very low level of CDKN2A, the gene coding for the MSC senescence marker $\mathrm{p} 16^{\mathrm{INK} 4 \mathrm{a}}$ (Figure S3) suggesting that they were not engaged into a senescence process ${ }^{24}$.

The GEP of resting HD-MSC and FL-MSC was determined at the end of P1 using Affymetrix U133 Plus 2.0 microarrays. Raw data were normalized using GC-RMA method and filtered to select the 9967 probesets (PS) showing the highest variation coefficient between samples. Strikingly, unsupervised hierarchical clustering analysis on this restricted dataset was able to perfectly segregate FL-MSC from HD-MSC (Figure 1a). To further delineate the specific GEP of FL-MSC, we then performed a supervised analysis by combining an asymptotic unpaired Mann-Whitney test and a SAM method. Based on this approach, we highlighted 408 PS representing the FLMSC signature and corresponding to 320 upregulated genes and 60 downregulated genes (Figure 1b and Table S3). Among them, 16\% were classified as coding for extracellular space or plasma membrane proteins (Figure S4). Interestingly, Ingenuity Pathway Analysis of this 408-PS list pointed out that the most significantly enriched 
biological functions were linked to hematological system development and function, hematopoiesis, and immune cell trafficking. The expression level of six genes was validated by $R Q-P C R$ and yielded concordant results. For this specific analysis, we selected two genes coding for factors potentially implicated in B-cell adhesion and growth (CHST2 and CLU), one gene involved in cell proliferation and differentiation (DUSP6), and three genes regulating host/tumor interface (TNFRSF10A, TLR4, and CCL2). Among them, CCL2 was the most significantly differentially expressed genes between FL-MSC and HD-MSC (Figure 1c).

\section{FL-MSC are committed to a FRC-like phenotype}

In $\mathrm{FL}$, invaded $\mathrm{BM}$ is infiltrated by lymphoid-like stromal cells of heterogeneous phenotype and unknown origin and function. We thus decided to examine if FL-MSC actually displayed some common genetic features with FRC. We first established the gene expression pattern of human FRC-like cells through the analysis of HD-MSC treated by TNF/LT for 3 days, a stimulation process previously associated with the in vitro differentiation into functional FRC-like cells ${ }^{12}$. After filtering the 8340 PS with the highest variation coefficient between samples, we underlined, by combining a paired t-test and a SAM method, 1673 PS representing the TNF/LT signature and corresponding to 811 upregulated genes and 431 downregulated genes (Figure 2a and Table S4). The expression level of seven genes identified by microarray strategy as highly induced by TNF/LT stimulation was validated by RQ-PCR (Figure 2b). Interestingly, TLR4 and CCL2 have been already pinpointed in the FL-MSC signature. Moreover, we also confirmed the upregulation of IL6, HBEGF, IL15, IL8, and CCL5 that were all involved in the recruitment and/or activation of immune cells. We next performed a Gene Set Enrichment Analysis (GSEA) approach in order to specifically assess the over-representation of the TNF/LT signature in FL-MSC. Interestingly, we found that FL-MSC GEP was significantly enriched in genes overexpressed in HD-MSC treated with TNF/LT (Figure 2c). In addition, among the 105 genes that were simultaneously found within the TNF/LT and the FL-MSC signatures, 101 were coordinately upregulated or downregulated in both HD-MSC treated by TNF/LT and FL-MSC (Figure S5 and Table S5). Finally, unsupervised hierarchical clustering revealed that the TNF/LT signature was sufficient per se to adequately segregate HD-MSC from FL-MSC (Figure 2d). 
As FL-MSC and HD-MSC have distinct molecular profiles, we performed functional coculture experiments to compare their respective capacity to reverse serum deprivation-induced growth arrest of GC-derived malignant B-cell lines. As previously reported $^{12}$, HD-MSC efficiently sustained the growth of neoplastic B cells, and preliminary treatment by TNF/LT reinforced this feeder effect by 2 -fold $(P<.01$; Figure 2e). Importantly, resting FL-MSC exhibited a significantly better B-cell supportive activity than HD-MSC (13310 cpm [7266-18400] versus 6663 cpm [53748264], $P<.001$ ) thus limiting the additional effect of TNF/LT prestimulation of FLMSC to a 1.26-fold increase. Altogether, these data argued for commitment of FLMSC towards a FRC-like phenotype consistent with their increased capacity to promote malignant B-cell growth.

\section{Monocytes are specifically recruited by FL-MSC and support FL cell growth}

We decided to focus on CCL2 as the master upregulated gene in FL-MSC and a high-ranked member of the TNF/LT signature. We first demonstrated that CCL2 was produced at a higher level in the supernatant of FL-MSC compared to HD-MSC (Figure 3a). Moreover, we quantified CCL2 in the BM plasma from $26 \mathrm{FL}$ patients and $31 \mathrm{HD}$ by ELISA and showed that CCL2 levels were variably but highly significantly increased in invaded BM compared to normal BM (474.4 pg/mL [5-4413] versus 33.6 $\mathrm{pg} / \mathrm{mL}$ [5-126.1]; Figure 3b), indicating that CCL2 could play a role in vivo within malignant cell niche. Of note, the three patients with FL grade 3a did not display a different CCL2 level in BM plasma compared to the 23 patients with FL grade 1-2.

CCL2 had no direct impact on lymphoma B-cell chemotaxis or survival as evaluated using both GC-derived B-cell lines and primary purified FL B cells (data not shown). However, FL-MSC recruited monocytes more efficiently than HD-MSC (Figure 3c). To ascertain whether CCL2 contributed to FL-MSC-dependent monocyte migration, we specifically depleted CCL2 from MSC supernatants. Interestingly, CCL2 depletion abolished monocyte recruitment. Taken together these results argued for a role of MSC-derived CCL2 on the cellular composition of FL microenvironment by attracting monocytes rather than for a direct activity on B-cell growth.

A high level of TAM has been correlated with bad outcome in patients with FL treated with chemotherapy ${ }^{27}$ but their involvement in FL B-cell growth has never been studied. We thus explored the growth-promoting activity of in vitro differentiated macrophages on 2 GC-derived B-cell lines. Macrophages sustained the growth of 
VAL and $\mathrm{RL}$ cell lines in low serum concentration as efficiently as FL-MSC. Moreover, FL-MSC and macrophages, previously maintained in coculture for 4 days to allow their crosstalk in vitro, exhibited a synergistic activity on malignant B-cell growth (Figure 4a). To further unravel the mechanism of this synergy, we specifically investigated both the survival and the proliferative capacities of FL-MSC, macrophages, and the combination of these two cell populations. Active caspase-3 staining revealed that FL-MSC abrogated spontaneous VAL B-cell apoptosis whereas the protective effect of macrophages was significantly lower $(42.9 \pm 18 \%$ for B cells alone versus $8.4 \pm 1.5 \%$ with FL-MSC versus $19.3 \pm 3.9 \%$ with macrophages, $P<.05$, Figure $4 \mathrm{~b}$ ). In contrast, when considering the percentage of BrdU ${ }^{\text {pos }}$ viable $\mathrm{B}$ cells, macrophages, unlike FL-MSC, increased VAL B-cell line proliferation (Figure 4c). Similar results were obtained using RL cell line (data not shown). Primary FL B cells are poorly proliferating and highly prone to apoptosis in vitro. In accordance, we were able to confirm the survival potential of FL-MSC and macrophages on malignant $B$ cells purified from 4 unselected FL patients but we could not detect any additional proliferative activity of the combination of both cell subsets (Figure 4d). Overall, these data supported the hypothesis that FL-MSC and macrophages cooperated to sustain malignant B-cell growth through protection from apoptosis and enhancement of proliferation.

\section{MSC drive monocyte differentiation towards a TAM-like phenotype}

BM-MSC affect the differentiation and function of dendritic cells and mature macrophages in vitro ${ }^{28}$. In addition, umbilical cord blood-derived MSC were recently reported to strongly reduce the T-cell stimulatory capacity of monocytes ${ }^{29}$. We therefore studied the phenotype of monocytes cocultured for $24 \mathrm{~h}$ and 7 days with FLMSC. After 24h, FL-MSC increased the expression of HLA-DR, CD86, and CD14 on monocytes and modulated their secretory profile through a strong inhibition of TNF secretion together with an increased of IL-10 release (Figure 5a). In addition, IL10, IL6, and VEGFA, which have already been involved in the proangiogenic and protumoral activity of TAM in several tumor models, were upregulated after 7 days of coculture in cell-sorted differentiated macrophages ( $<0.5 \%$ MSC contamination, Figure $5 b$ ). Interestingly, we reported for the first time the strong induction (519 fold [23-1160], $\mathrm{n}=9$ ) of $P G F$, the gene coding for placental growth factor, a member of the VEGF family that binds VEGFR-1 and forms functionally active heterodimers with 
VEGF- $A^{30}$. We next decided to evaluate the responsiveness of macrophages maintained in culture with FL-MSC to proinflammatory stimuli. Macrophages purified by cell-sorting after 7 days of coculture with FL-MSC have a reduced capacity to express pro-inflammatory and anti-inflammatory cytokines in response to LPS (Figure 5c). Similar results were obtained using HD-MSC and FL-MSC from grade 1, grade 2, and grade $3 a \mathrm{FL}$ patients (Figure S6).

The Notch pathway regulates cell differentiation, proliferation, and survival in numerous contexts. Notch1-4 receptors interact with Notch ligands of the Jagged and Delta-like families leading to the proteolytic cleavage of the Notch receptor by the $\gamma$ secretase, followed by the nuclear translocation of intracellular Notch domain. Recently, it has been reported that human BM-MSC and adipose tissue-derived MSC strongly express Jagged-1 and that Notch signaling is involved in their T-cell suppressive activity ${ }^{31,32}$. To explore the involvement of the Jagged/Notch interaction in the unresponsiveness of MSC-treated macrophages to LPS stimulation, we added DAPT, a highly selective $\gamma$-secretase inhibitor, during macrophage/MSC coculture. As shown in Figure $5 \mathrm{~d}$, the addition of DAPT significantly enhanced the capacity of macrophages cultured with FL-MSC to produce high amounts of TNF in response to LPS stimulation (1814 $\pm 1198 \mathrm{pg} / \mathrm{mL}$ with DAPT versus $530 \pm 374 \mathrm{pg} / \mathrm{mL}$ with DMSO versus $442 \pm 186 \mathrm{pg} / \mathrm{mL}$ with medium; $\mathrm{n}=10$ ). Interestingly, the production of IL-10 in response to LPS was also restored when the Notch pathway was inhibited during $\mathrm{MSC} /$ macrophage coculture (data not shown). HD-MSC modulated similarly the response of macrophages to LPS stimulation (data not shown).

In summary, monocytes exhibited a CD14 ${ }^{\text {hi }} C D 86^{\text {hi }}{ }^{2} L A-D R^{\text {hi }} T N F^{\text {Io }} / L-10^{\text {hi }}$ phenotype after a short course coculture with FL-MSC and HD-MSC and differentiated in 7 days into macrophages expressing high levels of proangiogenic factors and unresponsive to LPS stimulation. These data were strongly in favor of a TAM-like polarization.

\section{FL B cells promote CCL2 secretion by HD-MSC}

We next sought to assess whether malignant $B$ cells could be involved in the overexpression of CCL2 by FL-MSC. For that purpose, HD-MSC were cocultured with $T N F / L T$ as a positive control, as well as with various GC-derived B-cell lines and primary purified FL B cells. These experiments revealed an increased CCL2 secretion in the presence of malignant $B$ cells even if this induction was highly variable depending on the patient (from 1.1 to 42.3 -fold, $n=16$ ) and the cell line 
tested (Figure 6a). Interestingly, the coculture of the same primary FL B-cells with 2 different HD-MSC batches revealed intrinsically different capacity of malignant B cells to induce CCL2 production in HD-MSC with strong CCL2-inducers and poor CCL2inducers $B$ cells. To unequivocally identify the source of CCL2 within the coculture, HD-MSC were cocultured with B-cell lines before cell-sorting of CD19/CD20 ${ }^{\text {pos }} C D 105^{\text {neg }} B$ cells and $C D 19^{\text {neg }} C D 105^{\text {pos }} H D-M S C$. RQ-PCR analysis confirmed the strong upregulation of CCL2 in HD-MSC, unlike in purified B-cell compartment (Figure 6b). We investigated whether induction of CCL2 production in HD-MSC by malignant B cells was maintained in culture in the absence of continuous B cell-dependent stimulation. Interestingly, 10 days after B-cell removal, HD-MSC retained an increased CCL2 production compared to pure HD-MSC, indicating that the effect of $B$ cells was long-lasting (Figure 6c). Finally, we explored the functional relevance of this $B$ cell-mediated CCL2 induction and demonstrated that conditioned media from HD-MSC/B-cell cocultures recruited more efficiently purified monocytes than HD-MSC supernatant (Figure 6d). 


\section{Discussion}

In this study, we identify the specific gene signature of BM-derived FL-associated stromal cells. We demonstrate that this signature is related to that of lymphoid-like stromal cells, suggesting an ectopic engagement to FRC differentiation in vivo. Interestingly the presence of lymphoid-like stromal networks has already been reported in murine models of solid cancers where they contribute to the induction of an immunotolerant microenvironment ${ }^{9,10}$. These cells are supposed to be locally induced during cancer-related inflammation and an inflammatory gene signature has also been highlighted in fibroblasts obtained from mammary and pancreatic tumors in mice and humans where they promote angiogenesis and inflammatory cell recruitment ${ }^{33}$. Nevertheless, lymphoid-like differentiation is not a common feature of stromal cells in hematological malignancies. In particular, the already reported specific GEP of multiple myeloma $B M-M S C^{8}$ is not enriched for our FRC-like signature (data not shown), in agreement with the lack of morphologically detectable lymphoid-like structure in this disease. Importantly, in order to understand how malignant B cells could drive the emergence of an ectopic lymphoid-related stromal microenvironment, our study was performed on BM- unlike LN-MSC. However, CCL2 is also overexpressed in stromal cells derived from FL LN compared to stromal cells derived from chronically inflamed tonsils (data not shown) suggesting a general role of CCL2 within stromal cell niche in FL that is not only related to cancer-related inflammatory process.

We have previously demonstrated that FRC-like cells generated in vitro by stimulation of BM-MSC with TNF/LT are more powerful to drive malignant B cell survival than BM-MSC themselves ${ }^{12}$. Our current results reinforce and extend these data since we could establish that FL-MSC, already committed to a FRC-like differentiation, supported more efficiently the growth of malignant B cells. Similarly, MM-MSC were shown to overstimulate the proliferation of a MM cell line when compared to HD-MSC ${ }^{8}$. CCL2 had not direct impact on migration or survival of malignant FL B cells in agreement with the repression of CCR2 expression by Pax5 B-cell transcription factor ${ }^{34}$. The mechanisms of the direct tumor-promoting capacity of FL-MSC remain thus to be identified. However, FL-MSC also displayed indirect pro-tumorigenic effects including an increased capacity to recruit monocytes in a CCL2-dependent manner. CCL2 is one of the most frequently observed chemokines 
in a wide range of solid cancers where it harbors multifaceted activities by targeting both tumor cells and infiltrating myeloid cells. As an example, tumor-derived CCL2 recruits monocytes and promotes their survival and their polarization into CD14 ${ }^{\text {pos }}$ CD206 ${ }^{\text {pos }}$ M2-type macrophages in prostate cancer $^{35}$. Moreover, CCL2 synthetized by both the tumor and the stroma in a mouse model of breast cancer metastasis was recently involved in the early recruitment of CCR2 ${ }^{\text {pos }}$ VEGFA ${ }^{\text {hi }}$ inflammatory monocytes that contribute to the extravasation and seeding of tumor cells $^{36}$. In the same study, human inflammatory monocytes were shown to respond to the same CCL2-CCR2 axis for their recruitment into metastasis. Interestingly, it was recently suggested that perivascular BM stromal cells could sense circulating TLR ligands and, by producing CCL2, modulate the frequency of bloodstream inflammatory $\mathrm{CCR} 2^{\text {pos }}$ monocytes ${ }^{37}$. Our work reveals that BM-MSC could also induce CCL2-dependent monocyte migration in malignant context.

MSC have been shown to produce a variety of anti-inflammatory mediators, including prostaglandin E2 and TNF- $\alpha$ stimulated gene 6 (TSG-6/TNFAIP6), that promote macrophage reprogramming associated with the release of IL-10 and the decrease of inflammatory cytokines ${ }^{29,38,39}$. In agreement, we demonstrate in our current study that HD-MSC and FL-MSC alter the phenotype and secretory profile of macrophages, leading to a polarization into $\mathrm{TNF}^{\mathrm{lo}} \mathrm{IL}-10^{\text {hi }}$ VEGFA ${ }^{\text {hi }}$ PGF ${ }^{\text {hi }}$ LPS unresponsive TAM-like cells. Importantly, we highlight a key role for the Notch pathway in this process. In mouse macrophages, Notch activation promotes M1 polarization in response to LPS, a process supposed to be due to cooperation between Notch and NF- $\kappa B$ pathways ${ }^{40}$. However, in human macrophages, the functional outcome of TLR and Notch interactions is more complex since Notch target genes feedback and attenuate TLRinduced cytokine production ${ }^{41}$. In addition, human adipose tissue-derived MSC mediate a Jagged-1 related inhibition of $\mathrm{NF}-\kappa \mathrm{B}$ signaling in $\mathrm{T}$ cells ${ }^{32}$.

Besides the induction of a pro-angiogenic and anti-inflammatory profile on macrophages, coculture of MSC with macrophages give rise to a complex cell niche highly efficient in sustaining both survival and proliferation of malignant B cells. This synergy may be related to the crosstalk between the two cell partners, as recently suggested within hematopoietic stem cell niches where the interaction between macrophages and MSC regulates hematopoietic stem cell retention ${ }^{42}$. Multiple lines of evidence support the prominent role of TAM in the biology of FL, as highlighted by 
the poor predictive value of a high content of $C D 68^{\text {pos }}$ or $C D 63^{\text {pos }}$ cells in patients treated with chemotherapy ${ }^{27,43}$. Moreover, the activation status of TAM is probably crucial in FL, as reported in several other cancers. In particular, the presence of STAT1 $^{\text {pos }}$ TAM in FL was associated with an adverse outcome. Interestingly, the priming of macrophages with IFN- $\gamma$, which is overexpressed with $\mathrm{FL}$ microenvironment ${ }^{44}$, was shown to mediate a STAT1-dependent induction of CCR2 associated with an increased migration in response to CCL2 ${ }^{45}$. Such activation loop should be important for the recruitment of macrophages in close vicinity to stromal cell/malignant B cell aggregates. The precise mechanisms of the supportive activity of macrophages towards neoplastic B-cell remain unknown even if their production of $B$ cell-activating factor of the TNF family (BAFF) and a proliferation inducing ligand (APRIL) have been recently involved in diffuse large B-cell lymphoma and gastric mucosa associated lymphoid tissue (MALT) lymphoma ${ }^{46,47}$. Interestingly, we recently demonstrated that purified FL-TAM overexpress IL-15 that cooperates with T-cell derived CD40L signal to sustain FL cell growth ${ }^{48}$. A detailed analysis of FL-TAM would be very interesting to further understand their role in lymphomagenesis.

A key unsolved issue is how tumor-infiltrating stromal cells acquire their pro-tumoral phenotype and what could be the role of tumor cells in this process. In MM, adhesion of malignant plasma cells to BM stromal cells triggers the NF- $\mathrm{BB}$-dependent release of various cytokines, including IL-6 which in turn favors tumor cell growth ${ }^{49}$. Likewise, platelet-derived growth factor secreted by CLL B cells activates MSC to proliferate and produce VEGF, thus indirectly regulating angiogenesis and CLL disease progression $^{50}$. Our results reveal that CCL2 is induced in HD-MSC by coculture with malignant $B$ cells suggesting a bidirectional crosstalk between malignant $B$ cells and stromal cells. We previously showed that FL B cells significantly overexpress TNF compared to normal tonsil $B$ cells ${ }^{23}$ and the production of soluble TNF by normal $B$ cells is essential for the proper organization of secondary lymphoid organ microarchitecture $^{51}$. Since TNF/LT also induced CCL2 expression in MSC, it is tempting to speculate that TNF is, as least in part, involved in the upregulation of CCL2 by FL B cells. In agreement, antagonist anti-TNF receptor I protein strongly reduces the malignant $B$ cell-driven induction of CCL2 production by MSC (Figure S7). The already described wide disparity of TNF expression by malignant B cells ${ }^{23}$ could explain the strong variability of CCL2 induction in HD-MSC by FL B cells and could explain the heterogeneity of some functional data obtained in our study 
whereas we could not found any link, in our limited patient series, between FL grade 1 to $3 a$, that are now considered as equally indolent with indistinguishable clinical course $^{52}$, and either MSC properties or CCL2 concentration in FL BM. A detailed analysis of the genes induced in stromal cells by contact with malignant $B$ cells in response to TNF-dependent versus TNF-independent pathways is in progress. Besides malignant B cells, several other cell subsets could contribute to the modulation of FL-TAM phenotype and function. In particular, we recently unraveled a strong infiltration of invaded FL LN by IL-4-producing follicular helper T cells $\left(T_{F H}\right)^{53}$. In addition to its potential role in B-cell survival and proliferation, IL-4 is also known as a key inducer of TAM phenotype ${ }^{54}$. The presence and activation status of $\mathrm{T}_{\mathrm{FH}}$ or $\mathrm{T}_{\mathrm{FH}}$-like cells within invaded BM are currently unknown.

Altogether, these data highlight the complexity of FL tumors where stromal cells directly promote tumor growth and act also as global organizers of FL cell niches through the recruitment and polarization of macrophages. Additional experiments using purified FL-derived stromal cells obtained from invaded LN and BM would be helpful to address the specific role of MSC and their highly heterogeneous lymphoid progeny in FL development and drug resistance. The identification and characterization of this intricate network of cell interactions may provide novel strategies to disarm the tumor-promoting functions of stromal cells and could have significant therapeutic potential as a complement to conventional anti-lymphoma drugs. 


\section{Acknowledgments}

This work was supported by research grants from the Institut National du Cancer (INCa libre PL06-10 and PAIR Lymphome 2008-019), the Ligue Régionale Contre le Cancer, the Cancéropôle Grand Ouest, and the Association pour le Développement de l'Hémato-Oncologie (ADHO).

The authors thank Christophe Ruaux for providing tonsil samples, Veronique Quillien for providing elutriated monocytes, the BREHAT network for FL bone marrow samples, Sophie Belal for her help in obtaining mesenchymal stem cells, the "Institut Fédératif de Recherche (IFR)-140" of Rennes University for cell sorting core facility, and the "Centre de Ressources Biologiques (CRB)-Santé" of Rennes.

\section{Authorship contributions}

FG designed and performed research, and analyzed data

$\mathrm{GC}, \mathrm{CM}, \mathrm{PAT}, \mathrm{JD}$, and $\mathrm{CH}$ performed research

$\mathrm{CP}, \mathrm{JDV}$, and DR contributed to microarray experiments and statistical analysis

TL and OF organized sample collection and annotation

TF contributed to study design

KT designed and supervised research, analyzed data, and wrote the paper

Conflict-of-interest disclosure: The authors declare no competing financial interest. 


\section{References}

1. Hanahan D, Weinberg RA. Hallmarks of cancer: the next generation. Cell. 2011;144(5):646-674.

2. Mueller MM, Fusenig NE. Friends or foes - bipolar effects of the tumour stroma in cancer. Nat Rev Cancer. 2004;4(11):839-849.

3. Haviv I, Polyak K, Qiu W, Hu M, Campbell I. Origin of carcinoma associated fibroblasts. Cell Cycle. 2009;8(4):589-595.

4. Studeny M, Marini FC, Dembinski JL, et al. Mesenchymal stem cells: potential precursors for tumor stroma and targeted-delivery vehicles for anticancer agents. $J$ Natl Cancer Inst. 2004;96(21):1593-1603.

5. Mishra PJ, Humeniuk R, Medina DJ, et al. Carcinoma-associated fibroblastlike differentiation of human mesenchymal stem cells. Cancer Res. 2008;68(11):4331-4339.

6. Shinagawa K, Kitadai $\mathrm{Y}$, Tanaka M, et al. Mesenchymal stem cells enhance growth and metastasis of colon cancer. Int J Cancer. 2010;127:2323-2333.

7. Karnoub AE, Dash AB, Vo AP, et al. Mesenchymal stem cells within tumour stroma promote breast cancer metastasis. Nature. 2007;449(7162):557-563.

8. Corre J, Mahtouk K, Attal M, et al. Bone marrow mesenchymal stem cells are abnormal in multiple myeloma. Leukemia. 2007;21(5):1079-1088.

9. Peduto L, Dulauroy $\mathrm{S}$, Lochner $\mathrm{M}$, et al. Inflammation recapitulates the ontogeny of lymphoid stromal cells. J Immunol. 2009;182(9):5789-5799.

10. Shields JD, Kourtis IC, Tomei AA, Roberts JM, Swartz MA. Induction of lymphoidlike stroma and immune escape by tumors that express the chemokine CCL21. Science. 2010;328(5979):749-752.

11. Mueller SN, Germain RN. Stromal cell contributions to the homeostasis and functionality of the immune system. Nat Rev Immunol. 2009;9(9):618-629.

12. Amé-Thomas $\mathrm{P}$, Maby-El Hajjami H, Monvoisin $\mathrm{C}$, et al. Human mesenchymal stem cells isolated from bone marrow and lymphoid organs support tumor B-cell growth: role of stromal cells in follicular lymphoma pathogenesis. Blood. 2007;109(2):693-702.

13. Burger JA, Ghia P, Rosenwald A, Caligaris-Cappio F. The microenvironment in mature B-cell malignancies: a target for new treatment strategies. Blood. 2009;114:3367-3375.

14. Dave SS, Wright G, Tan B, et al. Prediction of survival in follicular lymphoma based on molecular features of tumor-infiltrating immune cells. $N$ Engl $J$ Med. 2004;351(21):2159-2169.

15. Relander T, Johnson NA, Farinha P, Connors JM, Sehn LH, Gascoyne RD. Prognostic factors in follicular lymphoma. J Clin Oncol. 2010;28(17):2902-2913.

16. Thomazy VA, Vega F, Medeiros LJ, Davies PJ, Jones D. Phenotypic modulation of the stromal reticular network in normal and neoplastic lymph nodes: tissue transglutaminase reveals coordinate regulation of multiple cell types. $\mathrm{Am} \mathrm{J}$ Pathol. 2003;163(1):165-174.

17. Lwin T, Hazlehurst LA, Li Z, et al. Bone marrow stromal cells prevent apoptosis of lymphoma cells by upregulation of anti-apoptotic proteins associated with activation of NF-kappaB (RelB/p52) in non-Hodgkin's lymphoma cells. Leukemia. 2007;21(7):1521-1531.

18. Lwin T, Crespo LA, Wu A, et al. Lymphoma cell adhesion-induced expression of $B$ cell-activating factor of the TNF family in bone marrow stromal cells protects non-Hodgkin's B lymphoma cells from apoptosis. Leukemia. 2009;23(1):170-177. 
19. Canioni D, Brice $P$, Lepage $E$, et al. Bone marrow histological patterns can predict survival of patients with grade 1 or 2 follicular lymphoma: a study from the Groupe d'Etude des Lymphomes Folliculaires. Br J Haematol. 2004;126(3):364-371.

20. Vega F, Medeiros LJ, Lang WH, Mansoor A, Bueso-Ramos C, Jones D. The stromal composition of malignant lymphoid aggregates in bone marrow: variations in architecture and phenotype in different B-cell tumours. $\mathrm{Br} J$ Haematol. 2002;117(3):569-576.

21. Bognar $A$, Csernus $B$, Bodor $C$, et al. Clonal selection in the bone marrow involvement of follicular lymphoma. Leukemia. 2005;19(9):1656-1662.

22. Tarte K, Gaillard J, Lataillade JJ, et al. Clinical-grade production of human mesenchymal stromal cells: occurrence of aneuploidy without transformation. Blood. 2010;115(8):1549-1553.

23. Maby-El Hajjami H, Ame-Thomas $\mathrm{P}$, Pangault $\mathrm{C}$, et al. Functional alteration of the lymphoma stromal cell niche by the cytokine context: role of indoleamine-2,3 dioxygenase. Cancer Res. 2009;69(7):3228-3237.

24. Shibata KR, Aoyama T, Shima $Y$, et al. Expression of the p16INK4A gene is associated closely with senescence of human mesenchymal stem cells and is potentially silenced by DNA methylation during in vitro expansion. Stem Cells. 2007;25(9):2371-2382.

25. Streubel B, Chott A, Huber D, et al. Lymphoma-specific genetic aberrations in microvascular endothelial cells in B-cell lymphomas. N Engl J Med. 2004;351(3):250259.

26. Coppe JP, Desprez PY, Krtolica A, Campisi J. The senescence-associated secretory phenotype: the dark side of tumor suppression. Annu Rev Pathol. 2010;5:99-118.

27. Farinha $\mathrm{P}$, Masoudi $\mathrm{H}$, Skinnider BF, et al. Analysis of multiple biomarkers shows that lymphoma-associated macrophage (LAM) content is an independent predictor of survival in follicular lymphoma (FL). Blood. 2005;106:2169-2174.

28. Uccelli A, Moretta L, Pistoia V. Immunoregulatory function of mesenchymal stem cells. Eur J Immunol. 2006;36(10):2566-2573.

29. Cutler AJ, Limbani V, Girdlestone J, Navarrete CV. Umbilical cord-derived mesenchymal stromal cells modulate monocyte function to suppress $\mathrm{T}$ cell proliferation. J Immunol. 2010;185(11):6617-6623.

30. Cao Y. Positive and negative modulation of angiogenesis by VEGFR1 ligands. Sci Signal. 2009;2(59):re1.

31. Liotta F, Angeli R, Cosmi L, et al. Toll-like receptors 3 and 4 are expressed by human bone marrow-derived mesenchymal stem cells and can inhibit their T-cell modulatory activity by impairing Notch signaling. Stem Cells. 2008;26(1):279-289.

32. Shi D, Liao L, Zhang B, et al. Human adipose tissue-derived mesenchymal stem cells facilitate the immunosuppressive effect of cyclosporin A on T lymphocytes through Jagged-1-mediated inhibition of NF-kappaB signaling. Exp Hematol. 2011;39:214-224.

33. Erez N, Truitt M, Olson P, Arron ST, Hanahan D. Cancer-Associated Fibroblasts Are Activated in Incipient Neoplasia to Orchestrate Tumor-Promoting Inflammation in an NF-kappaB-Dependent Manner. Cancer Cell. 2010;17(2):135147.

34. Delogu A, Schebesta A, Sun Q, Aschenbrenner K, Perlot T, Busslinger M. Gene repression by Pax5 in B cells is essential for blood cell homeostasis and is reversed in plasma cells. Immunity. 2006;24(3):269-281. 
35. Roca H, Varsos ZS, Sud S, Craig MJ, Ying C, Pienta KJ. CCL2 and interleukin-6 promote survival of human CD11b+ peripheral blood mononuclear cells and induce M2-type macrophage polarization. J Biol Chem. 2009;284(49):3434234354.

36. Qian BZ, Li J, Zhang $\mathrm{H}$, et al. CCL2 recruits inflammatory monocytes to facilitate breast-tumour metastasis. Nature. 2011;475(7355):222-225.

37. Shi C, Jia T, Mendez-Ferrer S, et al. Bone marrow mesenchymal stem and progenitor cells induce monocyte emigration in response to circulating toll-like receptor ligands. Immunity. 2011;34(4):590-601.

38. Nemeth K, Leelahavanichkul A, Yuen PS, et al. Bone marrow stromal cells attenuate sepsis via prostaglandin $E(2)$-dependent reprogramming of host macrophages to increase their interleukin-10 production. Nat Med. 2009;15(1):42-49.

39. Choi H, Lee RH, Bazhanov N, Oh JY, Prockop DJ. Anti-inflammatory protein TSG-6 secreted by activated MSCs attenuates zymosan-induced mouse peritonitis by decreasing TLR2/NF-\{kappa\}B signaling in resident macrophages. Blood. 2011;118:330-338.

40. Monsalve E, Ruiz-Garcia A, Baladron V, et al. Notch1 upregulates LPSinduced macrophage activation by increasing NF-kappaB activity. Eur J Immunol. 2009;39(9):2556-2570.

41. Hu X, Chung AY, Wu I, et al. Integrated regulation of Toll-like receptor responses by Notch and interferon-gamma pathways. Immunity. 2008;29(5):691-703. 42. Chow A, Lucas D, Hidalgo A, et al. Bone marrow CD169+ macrophages promote the retention of hematopoietic stem and progenitor cells in the mesenchymal stem cell niche. J Exp Med. 2011;208(2):261-271.

43. Clear AJ, Lee AM, Calaminici M, et al. Increased angiogenic sprouting in poor prognosis $\mathrm{FL}$ is associated with elevated numbers of CD163+ macrophages within the immediate sprouting micro-environment. Blood. 2010;115(24):5053-5056.

44. Alvaro T, Lejeune M, Camacho FI, et al. The presence of STAT1-positive tumor-associated macrophages and their relation to outcome in patients with follicular lymphoma. Haematologica. 2006;91(12):1605-1612.

45. $\mathrm{Hu} \mathrm{X}$, Park-Min $\mathrm{KH}, \mathrm{Ho} \mathrm{HH}$, Ivashkiv LB. IFN-gamma-primed macrophages exhibit increased CCR2-dependent migration and altered IFN-gamma responses mediated by Stat1. J Immunol. 2005;175(6):3637-3647.

46. Mueller CG, Boix $C$, Kwan WH, et al. Critical role of monocytes to support normal $B$ cell and diffuse large B cell lymphoma survival and proliferation. $J$ Leukoc Biol. 2007;82(3):567-575.

47. Munari F, Lonardi S, Cassatella MA, et al. Tumor-associated macrophages as major source of APRIL in gastric MALT lymphoma. Blood. 2011;117(24):6612-6616.

48. Epron G, Ame-Thomas P, Le Priol J, et al. Monocytes and T cells cooperate to favor normal and follicular lymphoma B-cell growth: role of IL-15 and CD40L signaling Leukemia. 2011. Prepublished on Jul 26, 2011, as DOI: 10.1038/leu.2011.179.

49. Hideshima T, Mitsiades C, Tonon G, Richardson PG, Anderson KC. Understanding multiple myeloma pathogenesis in the bone marrow to identify new therapeutic targets. Nat Rev Cancer. 2007;7(8):585-598.

50. Ding W, Knox TR, Tschumper RC, et al. Platelet-derived growth factor (PDGF)-PDGF receptor interaction activates bone marrow-derived mesenchymal stromal cells derived from chronic lymphocytic leukemia: implications for an angiogenic switch. Blood. 2010;116(16):2984-2993. 
51. Tumanov AV, Grivennikov SI, Kruglov AA, et al. Cellular source and molecular form of TNF specify its distinct functions in organization of secondary lymphoid organs. Blood. 2010;116(18):3456-3464.

52. Wahlin BE, Yri OE, Kimby E, et al. Clinical significance of the WHO grades of follicular lymphoma in a population-based cohort of 505 patients with long follow-up times. Br J Haematol. 2011. Prepublished on Nov 30, 2011, as DOI: 10.1111/j.13652141.2011.08942.x.

53. Pangault $\mathrm{C}$, Ame-Thomas $\mathrm{P}$, Ruminy $\mathrm{P}$, et al. Follicular lymphoma cell niche: identification of a preeminent IL-4-dependent $\mathrm{T}(\mathrm{FH})-\mathrm{B}$ cell axis. Leukemia. 2010;24(12):2080-2089.

54. Wang HW, Joyce JA. Alternative activation of tumor-associated macrophages by IL-4: priming for protumoral functions. Cell Cycle. 2010;9(24):4824-4835. 
Table 1. MSC growth and phenotype

\begin{tabular}{|c|c|c|c|c|}
\hline & & $\begin{array}{c}\text { Follicular lymphoma } \\
\text { patients }(n=10)\end{array}$ & $\begin{array}{l}\text { Healthy donors } \\
\qquad(n=6)\end{array}$ & $\mathrm{P}$ value \\
\hline Sex ratio $(M / F)$ & & $8 / 2$ & $4 / 2$ & \\
\hline Age * & & $58.5(42-76)$ & $54.0(30-78)$ & \\
\hline BM CFU-F * & & $52.5(10.5-625)$ & $161.7(23.5-506)$ & .3132 \\
\hline $\begin{array}{l}\text { Population } \\
\text { Doubling * }\end{array}$ & $\begin{array}{l}P D \text { at } P 0 \\
P D \text { at } P 1 \\
\text { Total } P D\end{array}$ & $\begin{array}{c}13.3(11-15.1) \\
5.1(3-5.8) \\
18.1(14.1-20.9)\end{array}$ & $\begin{array}{c}12.7(10.2-14.6) \\
5.4(4.3-6.1) \\
18(16.3-19.5)\end{array}$ & $\begin{array}{l}.8749 \\
.3831 \\
.8749\end{array}$ \\
\hline Karyotype & & $\begin{array}{l}46, X X[30](2) \\
46, X Y[30](8)\end{array}$ & $\begin{array}{l}46, X X[30](2) \\
46, X Y[30](4)\end{array}$ & \\
\hline $\begin{array}{l}\text { Phenotype at the } \\
\text { end of } \mathrm{P} 1^{* *}\end{array}$ & $\begin{array}{l}\text { CD45 } \\
\text { CD19 } \\
\text { CD105 } \\
\text { CD90 } \\
\text { CD73 } \\
\end{array}$ & $\begin{array}{c}0.2(0-0.5) \\
0.1(0-0.3) \\
99.9(99.1-100) \\
99.8(99.5-100) \\
99.8(99.5-100) \\
\end{array}$ & $\begin{array}{c}0.2(0-0.2) \\
0(0-0.2) \\
99.6(99.3-100) \\
99.9(99.8-100) \\
99.9(99.5-100) \\
\end{array}$ & \\
\hline
\end{tabular}

* data are expressed as median (range)

${ }^{* *}$ data are expressed as median percentage (range)

BM CFU-F = Number of CFU-F/10 ${ }^{6}$ BM mononuclear cells.

Total population doubling $(P D)=$ Cumulative number of PD (PD at P0 + PD at P1).

Standard karyotype was performed at the end of P1 by analyzing 30 RHG-banded metaphases. 


\section{Figure Legends}

Figure 1. FL-MSC display a specific gene expression profile

(a) Hierarchical clustering of resting untreated HD-MSC $(n=6)$ and FL-MSC $(n=10)$. Analysis was performed on the 9967 probesets (PS) showing the highest variation coefficient between samples. The relative level of gene expression is depicted according to the shown color scale.

(b) Schematic representation of the statistical analysis used to highlight the FL-MSC signature defined as the intersection of the two genelists generated by SAM analysis $(|\mathrm{FC}|>2$ and false discovery rate $(\mathrm{FDR})<5 \%)$ and Mann-Whitney rank test $(|\mathrm{FC}|>2$ and $P<.05)$.

(c) Validation by RQ-PCR of the overexpression of CHST2, CLU, DUSP6, TLR4, TNFRSF10A, and CCL2 in FL-MSC compared to HD-MSC. Each sample was normalized to GAPDH and the arbitrary value of 1 was assigned to the median expression of HD-MSC. ${ }^{*} P<.05 ;{ }^{* * *} P<.001$.

\section{Figure 2. FL-MSC are committed to a FRC-like phenotype}

(a) Schematic representation of the statistical analysis used to highlight the TNF/LT signature defined as the intersection of the two genelists generated by SAM analysis $(|\mathrm{FC}|>2$ and false discovery rate $(\mathrm{FDR})<.1 \%)$ and Mann-Whitney rank test $(|\mathrm{FC}|>2$ and $P<.005)$.

(b) Validation by RQ-PCR of the overexpression of TLR4, IL6, HBEGF, IL15, CCL2, IL8, and CCL5 in HD-MSC stimulated by TNF/LT for 3 days compared to untreated HD-MSC. Each sample was normalized to GAPDH and compared with expression in untreated HD-MSC. The results are the mean \pm SD obtained on 3 different HD-MSC.

(c) GSEA Enrichment Score (ES) curves for the TNF/LT signature in MSC samples using the SNR statistic to rank the genes. Vertical black lines indicate the position of each of the 811 non-redundant upregulated genes included in the TNF/LT signature and the green curve represents the running sum of the weighted ES.

(d) Hierarchical clustering of HD-MSC and FL-MSC performed on the 1673 PS of the TNF/LT signature. The relative level of gene expression is depicted according to the shown color scale.

(e) BL2 cell line was cultured in low serum concentration alone, or with confluent HDMSC $(n=9)$ or FL-MSC $(n=8)$, pretreated or not with TNF/LT. Tritiated thymidine $\left({ }^{3} \mathrm{H}-\right.$ 
TdR) incorporation was evaluated at day 3. MSC cultured alone always showed a ${ }^{3} \mathrm{H}-$ TdR incorporation $\leq 500 \mathrm{cpm} .{ }^{* *} P<.01 ;{ }^{* * *} P<.001$

Figure 3. CCL2 is overexpressed by FL-MSC and is involved in monocyte recruitment

(a) CCL2 production in culture supernatants from HD-MSC $(n=6)$ and FL-MSC $(n=9)$ was quantified by ELISA at the end of $\mathrm{P} 1$ and data are normalized by the number of cultured MSC. ${ }^{* *} P<.01$

(b) CCL2 was quantified in the bone marrow plasma obtained from $\mathrm{HD}(\mathrm{n}=31)$ and $\mathrm{FL}$ patients ( $n=26$, including 23 patients with FL grade 1-2 and 3 patients with FL grade 3a identified as white triangles). ${ }^{* * *} P<.001$

(c) Migration of purified peripheral blood monocytes in response to HD-MSC and FLMSC supernatants collected at the end of P1 and specifically depleted or not from CCL2 using magnetic beads. Monocyte migration index is calculated as the number of TOPRO- $3^{\text {neg }} C D 14^{\text {pos }}$ viable monocytes migrating in response to MSC supernatant divided by their number in response to migration medium. Results represent the mean \pm SD from 3 (HD-MSC) or 4 (FL-MSC) independent experiments. * $P<.05$

\section{Figure 4. FL-MSC and macrophages cooperate to sustain FL B-cell growth}

$(a, b, c)$ GC-derived B-cell lines were cultured in low serum concentration alone (CTRL), in the presence of FL-MSC, in vitro differentiated macrophages (Macro), or with a combination of Macro and FL-MSC that have previously established a bidirectional crosstalk during a 4-day coculture. (a) Cell growth was evaluated at day 3 on VAL (Left panel) and RL (Right panel) using tritiated thymidine ( $\left.{ }^{3} \mathrm{H}-\mathrm{TdR}\right)$ incorporation. Results represent the mean \pm SD from 6 experiments. MSC and macrophages cultured without $B$ cells always showed a ${ }^{3} \mathrm{H}-\mathrm{TdR}$ incorporation $\leq 500$ cpm. (b) Apoptosis was evaluated at day 1 on VAL using active caspase-3 staining gated on CD19/CD20 ${ }^{\text {pos }} B$ cells. Results represent the mean $\pm S D$ from 6 experiments. (c) Proliferation was evaluated at day 3 on VAL using BrdU staining gated on CD19/CD20 ${ }^{\text {pos }} B$ cells. Results represent the mean $\pm S D$ from 4 experiments. ${ }^{*} P<.05 ;{ }^{* *} P<.01$; ${ }^{* * *} P<.001$; ns: not significant.

(d) Purified B cells obtained from $4 \mathrm{FL}$ patients were cultured alone (CTRL), in the presence of FL-MSC, in vitro differentiated macrophages (Macro), or with a combination of Macro and FL-MSC that have previously established a bidirectional 
crosstalk during a 4-day coculture. The absolute number of B cells was assessed using TOPRO-3 staining and calibrated beads.

${ }^{* *} P<.01 ;{ }^{* * *} P<.001$.

Figure 5. FL-MSC drive monocyte differentiation to a TAM-like phenotype

(a) Early modulation of monocyte phenotype and secretory profile was evaluated after 24 hours of culture with or without FL-MSC. HLA-DR, CD86, and CD14 expression was evaluated by flow cytometry on CD1 $4^{\text {pos }} C D 105^{\text {neg }}$ TOPRO- $3^{\text {neg }}$ viable monocytes as the ratio of mean fluorescence intensity ( $\mathrm{MFF}$ ) compared to isotype control (Left panel). The production of TNF and IL-10 in the supernatant was simultaneously studied by ELISA (Right panel). Results represent the mean \pm SD from 5 experiments. ${ }^{*} P<.05 ;{ }^{* *} P<.001$.

(b) Late modulation of macrophage gene expression profile was evaluated after 7 days of coculture of monocytes with or without FL-MSC before cell sorting of CD14 ${ }^{\text {pos }}$ CD105 ${ }^{\text {neg }}$ TOPRO- $3^{\text {neg }}$ viable macrophages. Expression of IL10, IL6, VEGFA, and PGF was then evaluated by RQ-PCR. Each data was normalized to GAPDH and compared with expression in macrophage alone. The results are the mean \pm SD from 9 experiments. ${ }^{*} P<.05 ;{ }^{* *} P<.01 ;{ }^{* * *} P<.001$.

(c) Monocytes were cultured during 7 days with or without FL-MSC before stimulation or not by LPS during 5 hours. CD $14^{\text {pos }}$ CD $105^{\text {neg }}$ TOPRO- $3^{\text {neg }}$ viable macrophages were then cell-sorted and expression of TNF, IL10, and IL12A was evaluated by RQPCR. Each sample was normalized to GAPDH and compared with expression in unstimulated macrophages. The results are the mean \pm SD from 5 experiments.

${ }^{*} P<.05$.

(d) Monocytes were preincubated or not (MEDIUM) with DAPT or its vehicle (DMSO) for 1 hour, and cultured in the same conditions during 7 days with or without FL-MSC. LPS was then added or not (CTRL) during 18 hours and TNF concentration was measured in cell supernatants by ELISA $(\mathrm{n}=10)$. ${ }^{*} P<.05 ;{ }^{* *} P<.01 ;{ }^{* * *} P<.001$; ns: not significant.

\section{Figure 6. FL B-cells promote a prolonged CCL2 production by HD-MSC}

(a) HD-MSC were stimulated for 3 days by TNF/LT ( $n=3)$, or were cocultured with RL $(n=5)$, VAL $(n=5)$ or BL2 $(n=4)$ B-cell lines, or with purified primary FL B cells $(n=13)$. Three FL B cells were cocultured with 2 different HD-MSC (green triangles, blue 
squares, and red circles, respectively). CCL2 concentration was then measured in cell supernatants by ELISA and the results are expressed as the mean fold change compared to untreated HD-MSC. ${ }^{*} P<.05$; ${ }^{* * *} P<.001$; ns: not significant.

(b) HD-MSC were cultured for 3 days with RL or VAL before cell sorting of $C D 19 / C D 20^{\text {pos }} C D 105^{\text {neg }} D A P I^{\text {neg }}$ viable $B$ cells and $C D 19 / C D 20^{\text {neg }} C D 105^{\text {pos }} D A P I^{\text {neg }}$ viable MSC and quantification of CCL2 by RQ-PCR in each cell fraction. Same experiments were conducted with HD-MSC, RL, and VAL cultured alone. Each CCL2 $\mathrm{Ct}$ value was normalized to matched $G A P D H \mathrm{Ct}$ value. The results are the mean \pm SD from 3 experiments. ${ }^{*} P<.05 ;{ }^{* *} P<.01$.

(c) HD-MSC were cultured for 3 days with RL or VAL before collection of cell supernatant (Day 0). HD-MSC were then detached, depleted from residual B cells, and seeded again in culture for 10 days. CCL2 concentration was measured in Day 0 , Day 4 , and Day 10 cell supernatants by ELISA. Results are expressed as the fold change compared to untreated HD-MSC. Shown is one representative from two independent experiments.

(d) Migration of purified peripheral blood monocytes in response to supernatants from RL, VAL, HD-MSC, and HD-MSC maintained during 3 days in coculture with RL or VAL. Monocyte migration index is calculated as the number of TOPRO- $3^{\text {neg }} C D 14^{\text {pos }}$ viable monocytes migrating in response to cell supernatant divided by their number in response to migration medium. Results represent the mean \pm SD from 5 independent experiments. ${ }^{*} P<.05$ 


\section{Figure 1}

a.

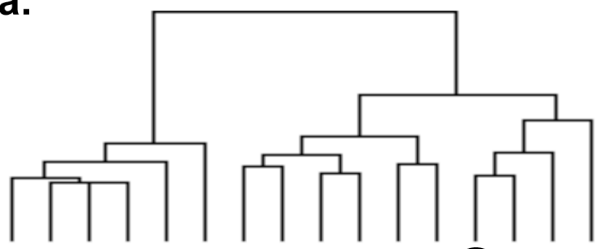

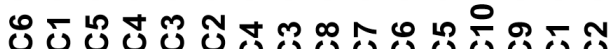
W

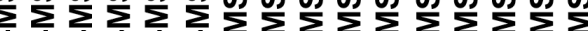

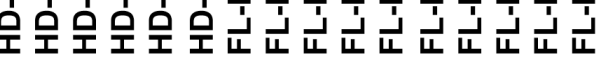

down

b.
Mann-Whitney
$P<.05$
SAM
FDR $<5 \%$

c.
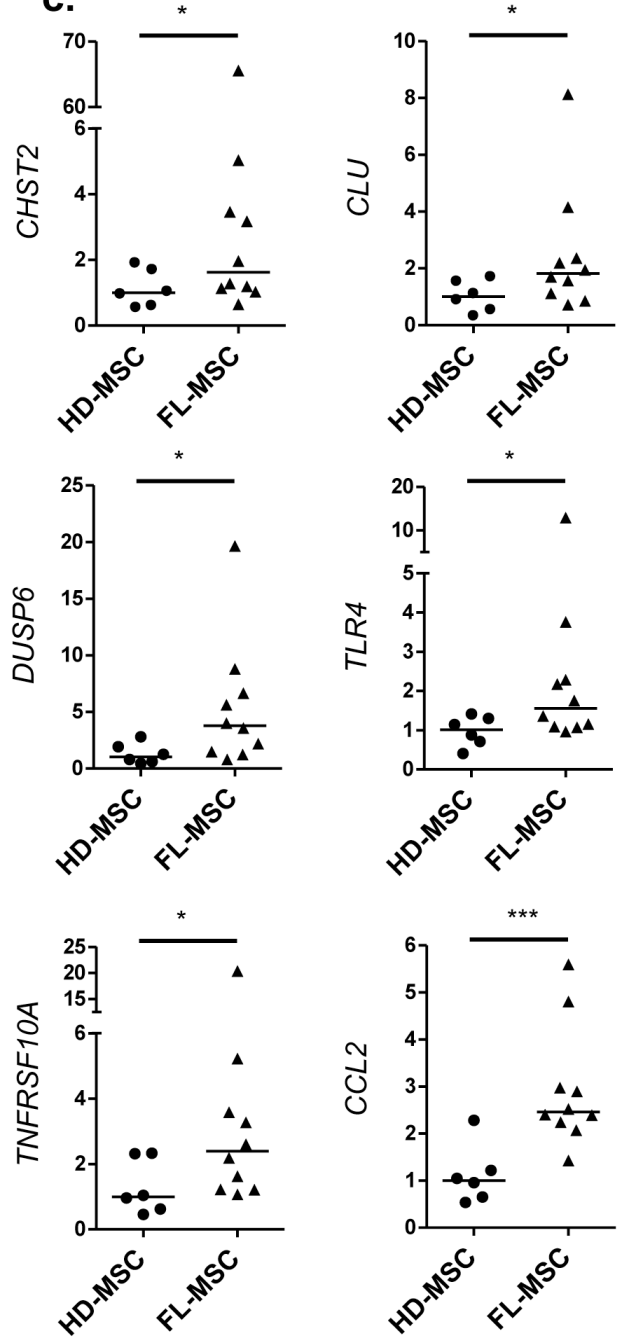

95 PS 408 PS 513 PS

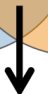

FL-MSC signature 320 upregulated genes 60 downregulated genes 


\section{Figure 2}

a. $\quad P a i r e d$ t-test
$P<.005$

SAM

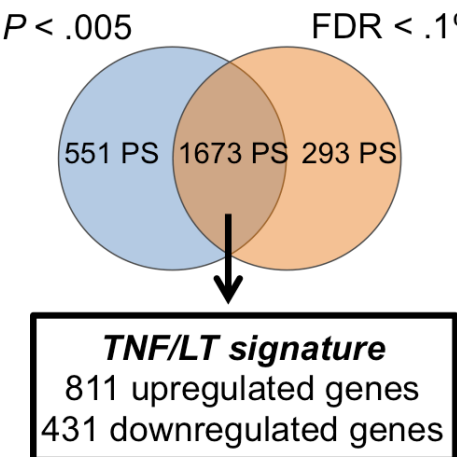

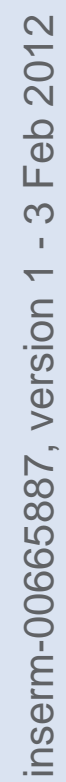

c.

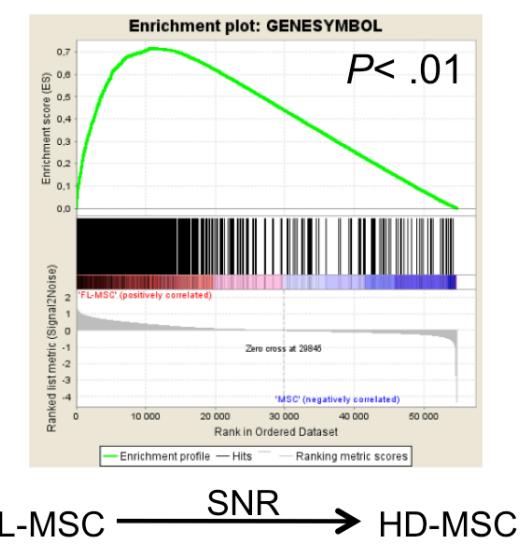

e.

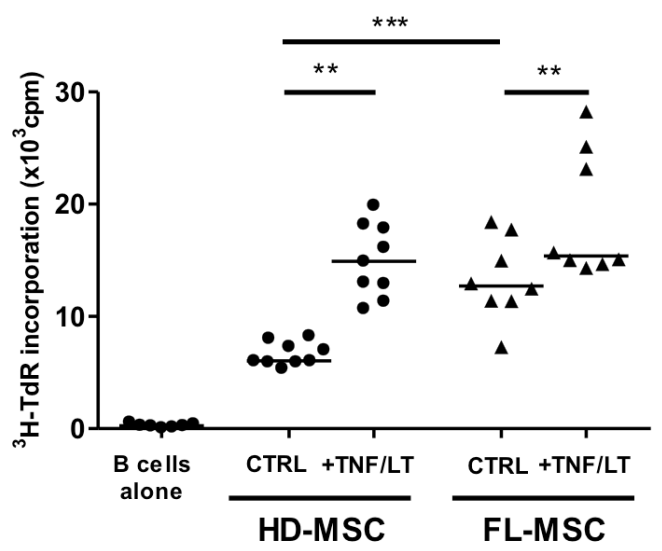

b.

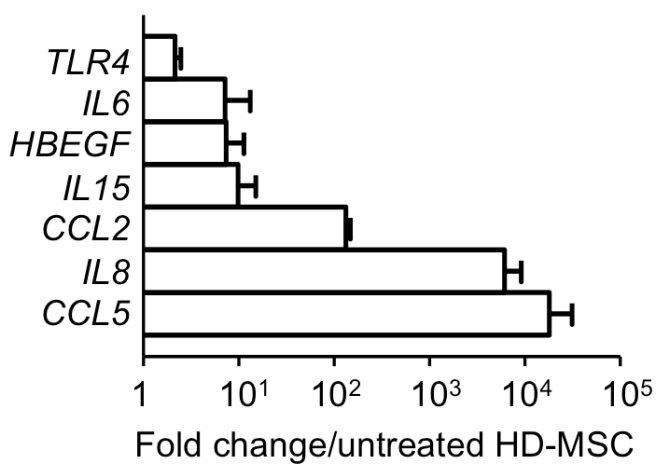

d.

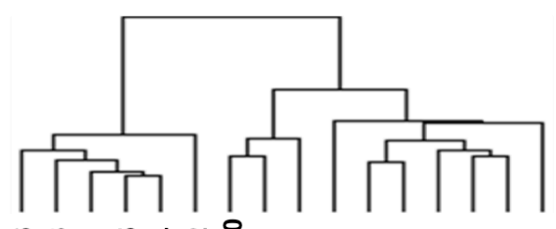

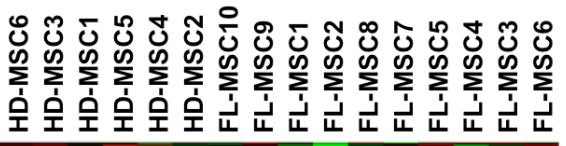

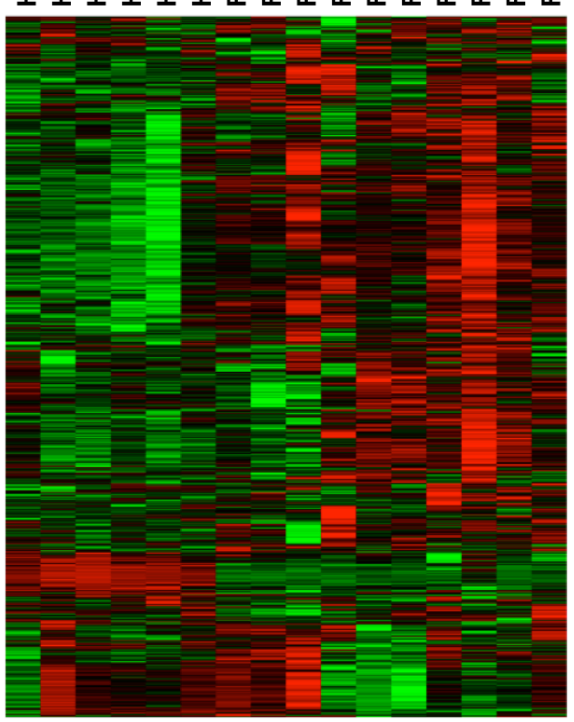

down

up 
Figure 3

a.

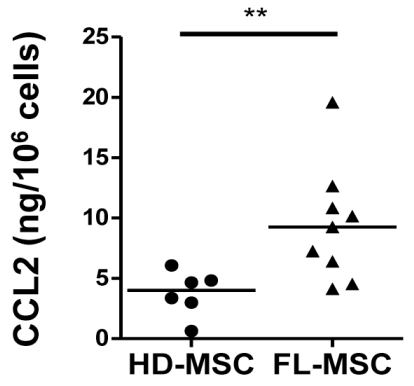

b.

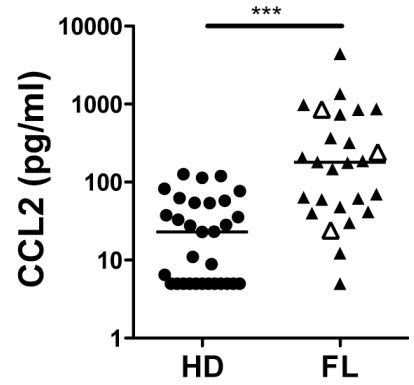

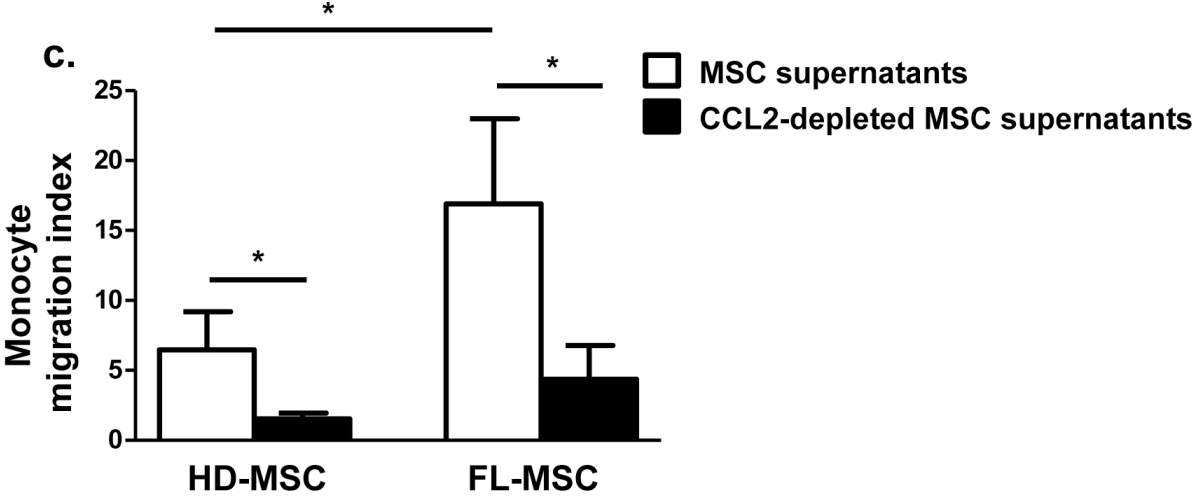


Figure 4

a.

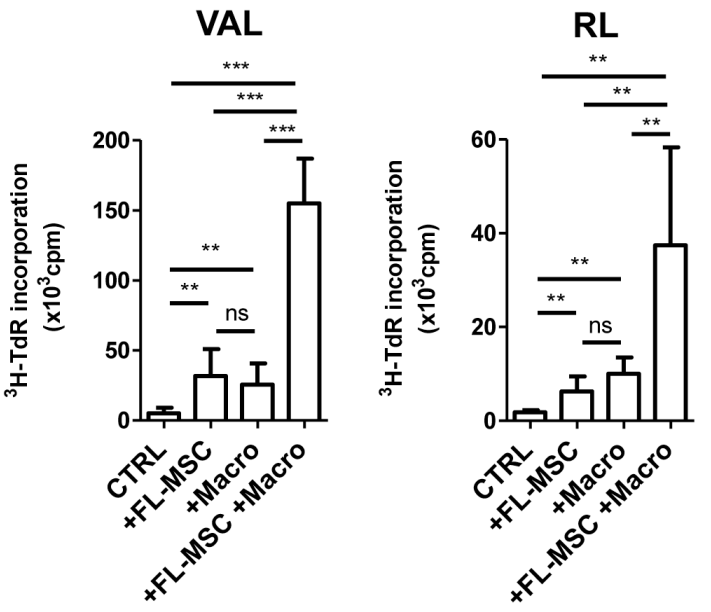

b.

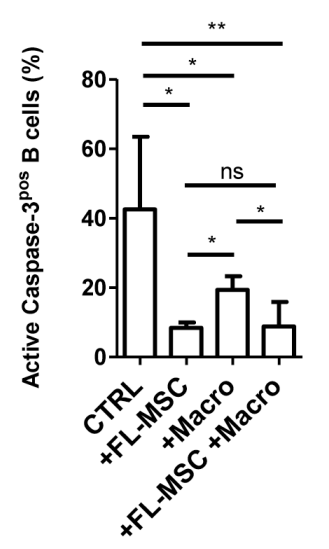

c.

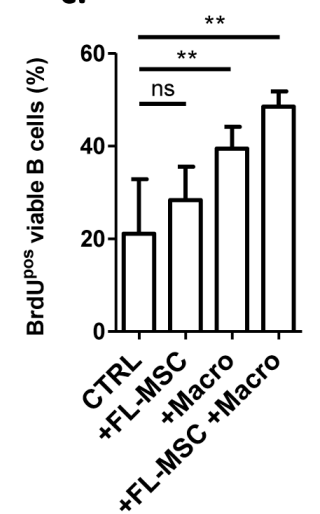

d.

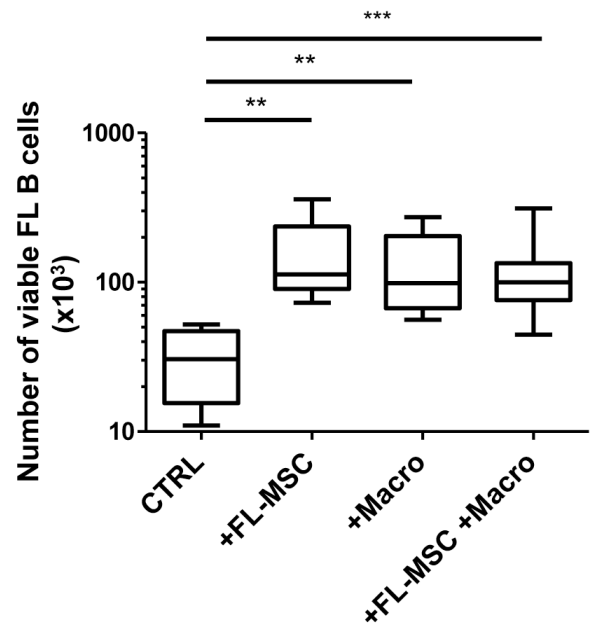


Figure 5
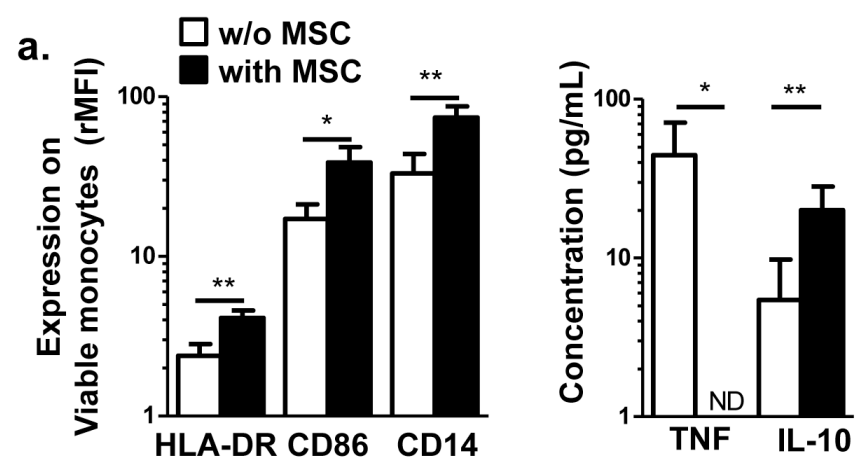

b.

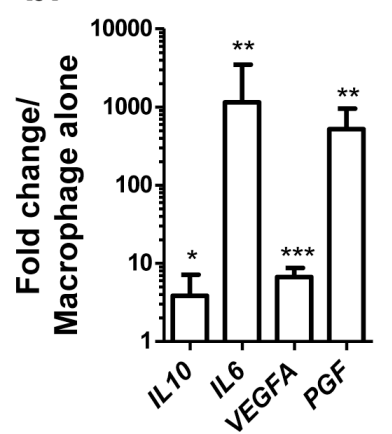

c.

d.

O w/o MSC

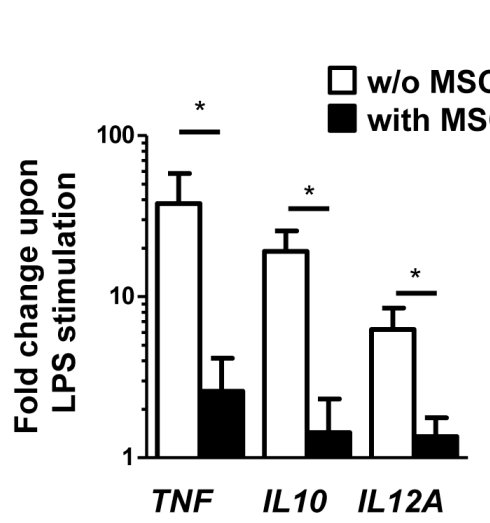

ns ** with MSC 


\section{Figure 6}

a.

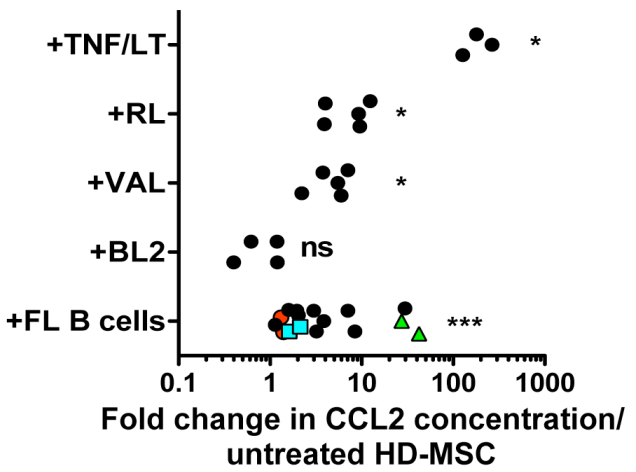

b.

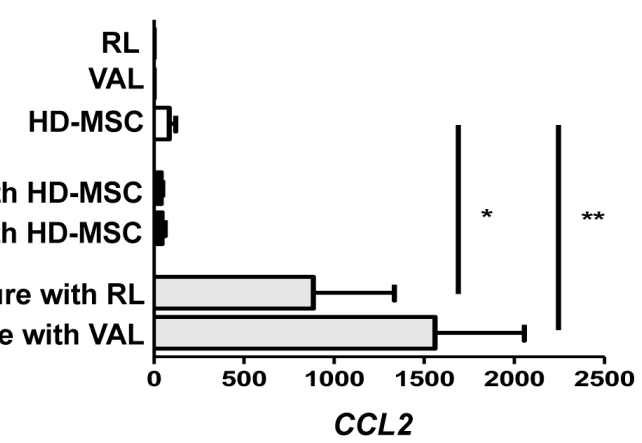

c.

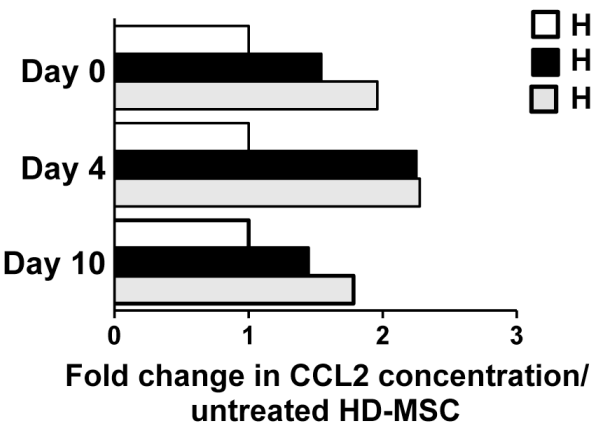

d.

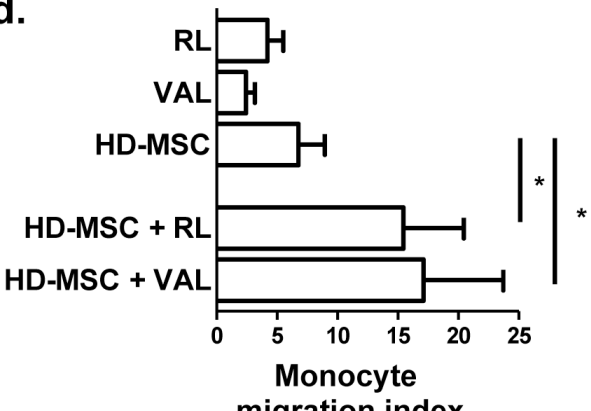

migration index 